UNIVERSITY OF GOTHENBURG

SCHOOL OF BUSINESS, ECONOMICS AND LAW

WORKING PAPERS IN ECONOMICS

No 600

\title{
Keeping others in our mind or in our heart? Distribution games under cognitive load
}

Karen Evelyn Hauge, Kjell Arne Brekke, Lars-Olof Johansson,

Olof Johansson-Stenman and Henrik Svedsäter

June 2014

ISSN 1403-2473 (print)

ISSN 1403-2465 (online) 


\title{
Keeping others in our mind or in our heart? Distribution games under cognitive load
}

\author{
Karen Evelyn Hauge ${ }^{1}$, Kjell Arne Brekke ${ }^{2}$, Lars-Olof Johansson ${ }^{3}$, Olof Johansson-Stenman ${ }^{4}$ and \\ Henrik Svedsäter ${ }^{5}$
}

\begin{abstract}
It has recently been argued that giving is spontaneous while greed is calculated (Rand et al. 2012). If greed is calculated we would expect that cognitive load, which is assumed to reduce the influence of cognitive processes, should affect greed. In this paper we study both charitable giving and the behavior of dictators under high and low cognitive load, to test if greed is affected by the load. In the dictator games we use both a give frame, where the dictators are given an amount that they may share with a partner, and a take frame, where dictators may take from an amount initially allocated to the partner. The results show consistently that the behavioral effect in terms of allocated money of the induced load is small if at all existent. At the same time, follow-up questions indicate that the subjects' decisions are more driven by their feelings and less driven by their thoughts under cognitive load.
\end{abstract}

JEL classifications: C91; D64

Keywords: Cognitive load, Dictator games, Social preferences, Pro-social behavior, altruism

Affiliations:

${ }^{1}$ Ragnar Frisch Centre for Economic Research, Gaustadalléen 21, 0349 Oslo, Norway, k.e.hauge@frisch.uio.no

${ }^{2}$ University of Oslo, Department of Economics, Postboks 1095 Blindern, 0317 Oslo, Norway, k.a.brekke@econ.uio.no

${ }^{3}$ University of Gothenburg, Department of Psychology, Box 100, S-405 30 Gothenburg, Sweden, larsolof.johansson@psy.gu.se

${ }^{4}$ University of Gothenburg, School of Business, Economics and Law, Department of Economics, Box 100, S-405 30 Gothenburg, Sweden, Olof.Johansson@economics.gu.se

5 London Business School, Regent's Park, London, NW1 4SA, United Kingdom, hsvedsater@london.edu

Corresponding author: Karen Evelyn Hauge,

Email: k.e.hauge@frisch.uio.no

Phone: 004741429619 


\section{Introduction}

Is moral behavior a result of cognitive processes? Haidt $(2001,2012)$ distinguishes between intuitive and rationalistic moral theory. The rationalist position argues that moral knowledge and moral judgments are reached primarily through a process of reasoning and reflection (Kohlberg 1969). Such reasoning is well known from texts that are thousands of years old and the discussion is still ongoing. The social intuitionist approach Haidt proposes, on the other hand, argues that moral evaluations are intuitively driven by effortless processes. ${ }^{1}$ We also find a similar discussion in economics. For example, van Winden (2007) argues that emotions are more important than cognition in individual enforcement of norms like fairness, whereas More and Loewenstein (2004) consider self-interested behavior as automatic and viscerally tempting while the concern for others is more cognitive in nature.

In dual process theory (e.g., Evans 2008; Kahneman 2003, 2012; Petty and Wegener 1999) the cognitive and intuitive processes are commonly seen as coexisting and being more or less active and parallel processes. Kahneman (2012, Chapter 1 ) uses the notion system 1 and 2 and defines them as: "System 1 operates automatically and quickly with little or no effort and no sense of voluntary control. System 2 allocates attention to effortful mental activities that demand it, including complex calculations." According to these theories, a number of factors, such as situation, type of decision, type of information, and mood, can influence whether cognitive or affective processes dominate a decision (Moskowitz et al. 1999; Stanovich and West 2000; Tversky and Kahneman 1974).

In a recent paper, Rand et al. (2012) find that subjects who make decisions faster are more cooperative in public goods games and prisoners' dilemmas. They suggest a dual process interpretation and propose that giving is spontaneous and greed is calculated. On the other hand, Piovesan and Wengstrøm (2009) find that shorter decision time is correlated with more egoism in dictator games, which would suggest that egoism is the intuitive response. Both papers use decision time as a proxy for cognition.

A different but somewhat related question is whether having social preferences, or more generally unselfishness, is a feature of the current organization of society or if it is more deeply rooted in human nature. A popular view is that pro-social behavior is a thin veneer of civilization above the selfish animal within, i.e., that social preferences are skin deep; this position is well summarized by biologist Michael Ghiselin (1974: 247): "Scratch an 'altruist' and watch a 'hypocrite' bleed." Others, such as primatologist De Waal $(1996,2006,2010)$, strongly reject this notion. He argues that we, together with primates and some other species, have a biologically determined sense of justice and capacity for experiencing empathy and sympathy, which in turn are crucial building blocks for morality. Then, he argues, if other primates, with less cognitive capacity and less developed cultures, have these capacities, it appears clear that human morality and various kinds of social preferences cannot be explained solely in terms of culture.

\footnotetext{
${ }^{1}$ In a much discussed study, Haidt et al. (2000) asked subjects to evaluate a story of a pair of siblings making love: "Julie and Mark are brother and sister. They are traveling together in France on summer vacation from college. One night they are staying alone in a cabin near the beach. They decided that it would be interesting and fun if they tried making love. At the very least it would be a new experience for each of them. Julie was already taking birth control pills, but Mark uses a condom too, just to be safe. They both enjoy making love but decide not to do it again. They keep that night as a special secret between them, which makes them feel even closer to each other. What do you think about that, was it OK for them to make love?" They find that subjects made moral judgments that they later were unable to support by moral arguments, and argue that this supports an intuitionist view of moral judgment.
} 
While the veneer theory is related, it is a separate claim. Cognitive processes are obviously rooted in our nature, and culturally transmitted norms may be internalized to the extent of being followed effortlessly. Still, if pro-social behavior is a thin veneer of civilization, the selfish urge must be controlled and behavior adjusted to what the rules of civilization demands. This would require traits many see as particular to humans: the ability to reason and deliberate. A related question is thus whether social preferences are primarily the result of cognitive reasoning.

We will not test the veneer theory in this paper. Instead, we want to test whether system 1 or 2 is dominating moral decisions by conducting an experiment where subjects make simple dictator choices under cognitive load, thus reducing the impact of system 2 . We manipulate cognitive capacity through cognitive load to test if this enhances or reduces greed. In comparison with other games such as ultimatum, public good, and trust games where generosity is clouded by strategic considerations, we have chosen dictator and charity games where strategic confounds are limited.

If cognitive capacity is constrained by performing cognitive tasks, it should reduce the influence of cognitive processes on other types of behavior. In order to reduce the available cognitive resources of our subjects, we have chosen a well-used method - memorizing a series of numbers - which we will refer to as cognitive load (e.g., Shiv and Fedorikin 1999). As we wish to reduce the available cognitive capacity and study how this affects behavior, we compare the behavior of subjects under high and low cognitive load.

Moreover, there is generally a great deal of evidence that "framing" (Tversky and Kahneman 1981) matters for experimental behavior. Behavior tends to depend on whether information is given in a positive or negative light as well as the wording used in the experiment (for examples of framing effects in public good games see Andreoni (1995), Sonnemans et al. (1998), and Cubitt et al. (2011); in dictator games, see Bardsley (2008); and for effects of different wordings see Ross and Ward (1996), and Liberman et al. 2004). One may argue that the framing may affect the perceived moral character of the problem. Indeed, subjects' moral judgments of free-riders in a public good game experiment varied according to whether the public good was described in positive or negative light (Cubitt et al. 2011). If subjects reframe in their mind, the reframing would reduce the effect of framing, but such a reframing requires cognition. One may thus conjecture that the effects of cognitive load may also be different depending on how a situation or decision is framed. We compare two frames: In the conventional give treatment, the individual decides how to split a certain amount of money that is given to him/her with an anonymous co-player, whereas in a take treatment the task is to take money initially given to the co-player.

Finally, we also analyze how the manipulation of cognitive load affects the emotions of subjects, based on a post-experimental survey to measure emotion.

The results consistently reveal no significant behavioral effects of cognitive load in our experiments regardless of framing. Thus, if such effects exist, they are small. The follow-up questions suggest that subjects under high cognitive load base their decisions more on feelings and less on reasoning, compared with those under low cognitive load. Subjects who reported that their decision was guided by feelings also tended to give more in the dictator game.

\section{Previous Studies}

The most common method of placing subjects under cognitive load consists of asking them to memorize a series of numbers; see, e.g., Swann et al. (1990), Gilbert et al. (1995), Trope and Alfieri 
(1997), Shiv and Fedorikhin (1999), and Shiv and Nowlis (2004). ${ }^{2}$ In an influential study by Shiv and Fedorikin (1999), people's possibility for self-control was studied under varying cognitive load; subjects under high cognitive load memorized 7 digits, while subjects under low cognitive load memorized 2 digits. Subjects were found to be more likely to choose a cake over a fruit salad when their cognitive ability was suppressed, indicating that cognitive reasoning is necessary for selfrestraint. In the present paper we utilize a similar design but investigate the effect of cognitive load on generosity instead of self-control.

There are relatively few studies measuring the effects of cognitive load on generosity and social preferences. Some previous studies find large and statistically significant effects, while others find small or no effects. Moreover, and somewhat problematic, the direction of these effects tend to vary.

Roch et al. (2000) undertook a variant of the public good game experiment, where subjects could withdraw resources from a common pool of 60 units. In their experiment, subjects were told that they were in a group of eight subjects, who each in turn could withdraw resources from the pool. Each subject was further told that $s /$ he was the first person in that group to choose how much to withdraw; hence, the subjects were clearly deceived in this respect, which is accepted in psychology, unlike economics. The treatment variable was whether subjects where under cognitive load or not; subjects under high cognitive load memorized an 8-digit number, while subjects under low cognitive load did not perform a memory task. The experimenters found that the subjects took half as much from the common pool under high cognitive load as under low cognitive load, suggesting that cognitive load leads to more generous behavior, or that generous behavior is instinctive or driven primarily by affective processes. Note that if the subjects in Roch et al.'s study wanted to share equally, they had to compute 60 divided by 8 and pick the closest integer, thus equal sharing may require cognitive capacity. Cognitive capacity may also affect the assessment of what the claimed next 6 subject will do.

Crelley et al. (2008) reported the opposite result in a more complex common pool experiment, using what they call ego depletion with the purpose of limiting the cognitive capacity for self control. In their experiment, all subjects were asked to imagine that they walked through a zoo, and their task was to register each time they thought of a white bear. Subjects under ego depletion were explicitly told that they should not think of a white bear, while nothing was said about the white bear in the other group. In their common resource experiment, there were several periods, and the remaining resource after each period grew at a $10 \%$ rate. They found that after ego depletion, withdrawal from the resource was more than twice as fast, with the resource lasting for about 10 rounds compared with more than 25 rounds with no ego depletion. Hence, cognitive load in terms of ego depletion led to more selfish behavior. However, note that the decisions require both computational abilities in calculating the consequences of early withdrawal and patience to wait for future rounds. The results may thus be explained without any references to social preferences.

Cappelletti (2011) studied the effect of cognitive load in an ultimatum game. In this study the high load treatment was to memorize 3-digit numbers and keeping them in mind making their decision in the ultimatum game, while there was no memory task in the low load treatment. They found no significant effect of cognitive load on either proposer or responder behavior. However, they also found that proposers offered more under a treatment with time pressure but argue that this seems

\footnotetext{
${ }^{2}$ Alternatives include letting subjects count the occurrence of a tone (Liebermann et al. 2001) or as in Gilbert and Krull (1988) let subjects watch letters flashing by on a screen.
} 
to be due to strategic considerations rather than other-regarding concerns. Respondents were found to be more likely to reject offers under time pressure, which may be interpreted as a greater concern for fairness.

The studies closest to ours are Benjamin et al. (forthcoming) and Cornelissen et al. (2011), who both studied contributions in dictator games under cognitive load. Benjamin et al. used a small sample (37) of people, where dictators also acted as recipients. Half of the subjects in their experiment were asked to memorize string of seven digits. They found that dictators were slightly less generous, although not statistically significantly so, under cognitive load.

Cornelissen et al. (2011) conducted a series of experiments, with students signing up as part of a mandatory course requirement. They arrived at the lab in groups of 8 and were assigned roles as dictators whose task was to choose how much out of a dollar to be donated to the alleged recipients (in reality no recipient existed). In these experiments, half of the subjects were asked to memorize a random seven digit number (5684524), while the other half were asked to memorize a structured sequence of seven digits (1234567). The numbers were shown on a screen for 8 seconds. After the dictator game, they completed a questionnaire aimed to categorize subjects in terms of their social value orientations as being either pro-selves or pro-socials. A more complex pattern emerged. Pro-selves on average donated 1.53 coins in the load treatment and 1.83 coins in the noload treatment. Pro-socials on average donated 2.45 coins in the load treatment and 1.85 coins in the no-load treatment. Overall, the positive effect of a cognitive load for pro-socials dominated the smaller negative effect for pro-selves, implying an overall positive but insignificant effect. Provided that cognitive load accentuates emotional processes, this result seems to suggests that pro-selves are intuitively guided by self-interest whereas pro-socials are intuitively guided by fairness concerns, and that cognitive processes moderate this distinction.

Few studies have looked directly at the relation between emotions and behavior in allocation decisions. One exception is a study by Pillutla and Murnighan (1996), where anger was found to explain rejections in ultimatum games. Another is a study by Johansson et al. (2010), where managers made choices between alternatives implying equal and unequal rewards to subordinates. The managers' emotional responses to inequality of rewards were also measured. The results showed stronger outward-directed negative emotions (such as anger) and inward-directed negative emotions (such as guilt) and weaker inward-directed positive emotions (such as pride) when inequality of rewards increased. Negative emotions in particular were found to explain the managers' aversion to inequality.

In economics, some experiments have looked into response times for decisions. If instinctive choices are made faster while deliberating is more time consuming since it requires cognitive processing, the response times of different choices may give information about instinctive versus cognitive preferences. Piovesan and Wengström (2009) measured response times in a dictator game and found that selfish choices are made faster than generous choices. This might point in the direction of social preferences being based on cognitive processes. On the other hand, Rand et al. (2012) found that shorter decision times are correlated with cooperation in one-shot public good games and prisoner's dilemmas. They conducted several experiments. First they compared subjects who decided faster than the median with those who decided slower. They also compared imposed time constraints and imposed time delay, and used varieties of the games with and without punishment. The faster decisions were significantly more cooperative in all cases. They also primed subjects to either use intuition or deliberation and found that intuitive priming led to more cooperative responses. Tinghög et al. (2013) challenged their interpretation of the time constraint experiments and conducted a series of similar experiments with no effect. Rand et al. (2012) interpreted their experiments as showing that greed is calculated while giving is spontaneous. 
Schultz et al. (forthcoming) also analyze a version of the dictator game under cognitive load. They used a cognitive load in the form of an n-back task (Gevins and Cutillo 1993), where subjects hear a series of letters and have to press a button whenever a letter matches the one from two steps earlier in the sequence. The authors argue that this task is likely to impose a higher cognitive load than memorizing numbers. The subjects in their study could choose between a fair (equal split) and an unfair allocation. The subjects in the high-load condition were found to choose the fair allocation more often than subjects in a low-load condition.

Overall, previous studies point in opposite directions regarding the effects of cognitive load. Some indicate that generosity is automatic while others suggest it is deliberate. Since several of the previous studies used rather complex designs, and sometimes confounded by strategic elements, we believe it is worthwhile to utilize a simpler design where strategic considerations are minimized.

\section{The Experimental Design}

\subsection{Experiment 1}

Experiment 1 was conducted at the Stockholm School of Economics in April 2008. In total 57 subjects recruited from Stockholm School of Economics participated. There were 4 sessions, each involving $22,9,21$, and 5 subjects. In the first three sessions every second subject received the low and high cognitive load treatment, while in the last session all 5 subjects received the high cognitive load treatment, yielding 25 subjects in the low cognitive load treatment and 32 subjects in the high cognitive load treatment.

The purpose of this experiment is to examine the effect of cognitive load on the willingness to donate money to a charity. Experiment 1 essentially is a dictator game experiment with a charity as the receiver; cf. Eckel and Grossman (1996). The design largely follows that used by Shiv and Fedorikin (1999), with the important modification that we measure the difference in generosity rather than self-control under cognitive load. In Experiment 1, subjects are asked to divide SEK $100^{3}$ between themselves and a charity (the Red Cross), after having memorized a 7-digit number. The treatment variable is the complexity of the memory task. In the low cognitive load treatment, the 7digit numbers were easy to memorize (9999999 or 1234567), while in the high cognitive load treatment, the 7-digit numbers were more difficult to memorize (9824672 or 1642753). Memorizing the more difficult numbers presumably requires much more of a person's cognitive resources than memorizing the simple numbers. Whereas Shiv and Fedorikin (1999) use a 2-digit number in their low cognitive load treatment and a 7-digit number in their high cognitive load treatment, we chose to use 7-digit numbers in both treatments to avoid any anchoring effects (Tversky and Kahneman 1974). A second measure to avoid anchoring effects was to let the first digit of the 7-digit numbers within each session be identical (for instance 9999999 vs. 9824672). To avoid the possibility of subjects learning the memory task before the experiment started from subjects who participated in earlier sessions, the memory task was different on every new day of the experiment. The experiment was conducted as described below.

All subjects met in a common room where oral instructions were provided. Subjects were informed that part of the experiment would take place in a different room, and that they therefore would be

\footnotetext{
${ }^{3}$ One USD was equivalent to roughly SEK 7 at the time of the experiment.
} 
asked to go to another room during the experiment. They were told that they would be given a choice of payment for participating in the experiment. Further, they were told that they would be asked to memorize some numbers, and that later in the experiment they would be asked to report the numbers that they had memorized. Reporting the numbers correctly increased their total payoff by SEK 50. In addition, all subjects received a show-up fee of SEK 50.

Subjects were instructed to come forward one by one. Each subject was then shown a card with a 7digit number, and asked to memorize this sequence. Similar to Shiv and Fedorikhin, there was no time limit for how long time subjects could use to memorize the numbers. After memorizing the numbers, each subject left the first room and proceeded to a booth that was situated in the hallway between the two rooms. On the wall inside the booth, there was a poster informing subjects that their choice was to divide SEK 100 between themselves and the Red Cross. The SEK 100 could be divided in intervals of SEK 20. On a table inside the booth there were 6 piles of paper slips, one pile for each of the 6 alternatives. Subjects were informed that they should pick the paper slip that indicated their choice and hand it over at their arrival in the second room. The piles of paper slips were such that subjects were not able to infer the choice of previous subjects.

At arrival in the second room, each subject delivered the paper slip indicating his/her chosen payoff, reported the memorized numbers, and accordingly received payment in cash. Each subject then received a questionnaire, which $\mathrm{s} /$ he completed in privacy before leaving the experiment.

In the post-experimental survey, subjects were asked to rate on a 7-point scale how five word pairs influenced their choice: "My final choice was decided by" my thoughts (1)/my feelings (7), my willpower (1)/my desire (7), my prudent self (1)/my impulsive self (7), the rational side of me (1)/the emotional side of me (7), my head (1)/my heart (7) (adopted from Shiv and Fedorikhin (1999)). Then subjects were asked to imagine two hypothetical situations; the first situation they were asked to imagine was that they gave all 100 SEK to the Red Cross and the second situation was that they gave nothing to the Red Cross. For each of the two hypothetical situations, subjects were asked to report how different emotions ${ }^{4}$ were associated with the situation on a 7-point scale ${ }^{5}$ and to report, again on a 7-point scale, how different thoughts ${ }^{6}$ were associated with the situation. Finally, subjects were asked to indicate on a 7-point scale how different word pairs described themselves; whether they were thoughtful (1)/impulsive (7), patient (1)/impatient (7), stingy (1)/generous (7), like to take risks (1)/afraid of risk (7). The entire instructions and post-experimental survey can be found in the Appendix.

\subsection{Experiment 2}

Due to the limited effect of cognitive load in Experiment1, and given the mixed findings reported in the literature, we decided to improve the design and increase the number of subjects. The settings were therefore simplified to a well-established experimental setup in which we examined the effect of cognitive load on behavior in a standard dictator game where the receiver, instead of being a charity as in experiment 1 , now was a subject in the experiment. In addition, we decided to increase the level of difficulty of the cognitive load task since most subjects succeeded in the memory task in

\footnotetext{
${ }^{4}$ Irritation, anger, contempt, envy, guilt, jealousy, sadness, joy, pride, happiness, shame, fear, and surprise (emotions adopted from Bosman and van der Winden (2002)).

${ }^{5} 1$ indicated "no such feeling" and 7 indicated "a strong such feeling".

${ }^{6} \mathrm{~A}$ useful choice/a useless choice, a rational choice/an irrational choice, an uncertain choice/a safe choice, a disadvantageous choice/an advantageous choice, an inadequate choice/a perfect choice (adopted from Crites et al. (1994)).
} 
Experiment 1. Instead of memorizing 7 digits, subjects now memorized a combination of 7 digits and letters.

Experiment 2 was conducted at the University of Oslo in October 2008. Students were recruited at various large lectures for first-year students. A total of 122 subjects participated, 61 as dictators and 61 as receivers. In total four sessions were run, each with $80,75,90$, and 60 subjects.

There were two different manipulations: high versus low cognitive load and a give versus take framing of the dictator game. The low cognitive load task was to memorize a simple combination of 7 digits and letters (AAAA111 or BBBB111), while the high cognitive load task was to memorize a more difficult randomly generated combination (1GT6N58 or 3H4BS92). Subjects were given 15 seconds to memorize the memory task. The second manipulation was the framing of the dictator choice. In both framings, dictators were given two envelopes, one marked "For me" and the other marked "For my partner", where one of the envelopes contained 10 small sheets of paper each worth NOK 30 (about $5 \$)$ and the other envelope was empty. In the give frame, the paper slips were placed in the envelope marked "For me", while in the take frame the paper slips were placed in the enveloped marked "For my partner". Each dictator could divide the NOK 300 between himself and the receiving partner by moving the preferred number of paper slips between the envelopes.

The procedure of the experiment was as follows. At arrival at the experiment, all subjects drew a number indicating their seat number. In each session all subjects were first gathered in a common room where the initial instructions were presented orally, informing them that their payoff would depend on decisions made by half of the subjects present, in addition to an individual memory task. After the initial instructions were given, all subjects who had drawn an odd number were asked to go to a second room. The subjects who left the room were assigned the role as receivers, while the subjects who remained in the first room were assigned the roles as dictators. The random draw of seat numbers ensured that subjects were assigned randomly to the role as dictators and receivers. Gathering all subjects in a common room at the beginning of the experiment also demonstrated to the dictators that the receivers were real subjects in the experiment. All subjects completed two memory tasks and two decisions. The procedures were similar for both these parts of the experiment. In both parts, the memory task was shown on the screen for 15 seconds, the instructions for dictator choice were read out loud, and then subjects made their decisions and handed in their envelopes before receiving pen and paper for reporting the memory task. In part 1 all subjects also made a decision regarding the timing of payment before reporting the memorized sequence. The timing decision is described below.

The memory tasks were identical for dictators and receivers participating in the same treatment, while the decisions were different. Subjects were not allowed to have any belongings on their desk. This was to avoid subjects writing down the memory task on paper, phones, or computers. For all dictators regardless of cognitive load manipulation, decision 1 was a dictator choice with a take frame while decision 2 was a dictator choice with a give frame. For all receivers regardless of cognitive load manipulation, decision 1 was to report what they considered to be the morally right distribution of NOK 300 between themselves and another anonymous person, and decision 2 was a hypothetical dictator choice. Thus, the cognitive load manipulation implies between-subject comparisons, while the framing manipulation implies within-subject comparisons.

After completing decision 1, and before reporting the first memory task, all subjects were given the choice between receiving their payoff today or receiving $33.3 \%$ more if opting to be paid in one month after the experiment. This enables us to measure whether cognitive load effects patience. As this decision was made while subjects were under cognitive load, subjects used stickers (and not pens) to indicate their choices on the answering sheet, in order to avoid subjects writing down the memory task before they were due to report it. 
Only one of the dictator choices was actually paid out, and a dice roll determined which of the two rounds would determine payments. After determining which round should be used for payment, the receivers received the envelope marked "For my partner" from their partner in the corresponding round. All payoffs were transferred to the subjects' bank account either the day of the experiment or one month later according to the request of each subject.

In the post-experimental survey, subjects were asked to rate to what degree ${ }^{7}$ they experienced several emotions while they made the last dictator choice in the experiment. The selected emotions were both positive and negative emotions taken from a question battery well-known within psychology called the PANAS-X (Watson and Clark 1994). We also revised one of the questions from the post-experimental survey in experiment 1 (from Shiv and Fedorikhin (1999)). Instead of forcing subjects into a dual mind by putting word pairs up against each other on a 7-point scale (for instance "My decision was guided by: my emotions (1)/my thoughts (7)"), subjects were asked to rate each word by itself on a 5-point scale ${ }^{8}$. Dictators were also asked to report what they personally found to be morally right behavior in the dictator game (receivers answered this question during the experiment). The complete instructions and post-experimental survey can be found in the Appendix.

\subsection{Experiment 3}

Experiment 3 was again set up as a simple dictator game. Our aim here was to simplify the experimental procedures even further. Compared with Experiment 2, we performed each experimental session in a single (large) room. Furthermore, in order to make it even more salient that the choices entailed real monetary trade-offs, subjects were now paid in cash. Moreover, while the envelopes contained play money (paper slips) in Experiment 2, they now contained real bank notes. Finally, whereas Experiment 2 used a lottery to determine which of the two choices would be paid out, in Experiment 3 all choices were paid out.

Experiment 3 was conducted at the University of Gothenburg in December 2008 and March 2009. Altogether 146 students participated in the experiment. Students were first contacted via e-mail, asking them whether they were interested in participating in an experiment conducted at the university. Interested students were randomly divided into four groups and were then given a time and place where the experiments were to take place. Four identically designed sessions were run (two sessions in December and two in March), conducted subsequently to each other as classroom experiments.

As in Experiment 2, we used two different manipulations: high vs. low cognitive load and a give vs. a take framing. The low cognitive load task was to memorize a simple combination of 7 letters (AAAAAAA), while the high cognitive load task was to memorize a more difficult combination of 7 digits and letters (8Z3QC9S). In both cases, subjects were given 15 seconds to memorize the combination. Subjects who remembered the combination correctly at the end of the experiment were paid SEK 50. The decisions in Experiment 3 were, as in Experiment 2, framed as either give or take scenarios. While dictators in Experiment 2 made one dictator decision for each of the framing scenarios, in Experiment 3 each dictator only made one decision. This implies a between-subject comparison for both manipulations in Experiment 3. For half of the subjects the envelope marked "For me" contained eight SEK 20 notes, i.e., in total SEK 160, whereas the envelope marked "For my partner" was empty (give scenario). The subject could then move as many SEK 20 notes as s/he wished to the partner's envelope. For the remaining subjects, the envelope marked "For my partner"

\footnotetext{
${ }^{7}$ Five-point scale: 1) Very slightly or not at all 2) a little, 3) moderately, 4) Quite a bit, 5) extremely.

${ }^{8}$ Five-point scale where 1 corresponds to "Does not coincide" and 5 corresponds to "Coincides very well".
} 
contained eight SEK 20 notes, whereas the envelope marked "For me" was empty (take scenario), whereby the subject could move as many SEK 20 notes as s/he wished between the envelopes. They were finally told to keep the envelope marked "For me" and leave the envelope marked "For my partner" on their desk, which was later collected by us.

The subjects in the first treatment were dictators under low cognitive load, while subjects in the second treatment were dictators under high cognitive load. The dictators were told that the partner was a randomly selected individual who was to conduct a similar task in a later session the same day.

In the remaining two sessions subjects were receivers, in the third treatment under low cognitive load and in the fourth under high cognitive load. As such, they made no consequential decisions. Instead, they were instructed to make an allocation decision in a hypothetical dictator game, with the only difference being that they used (obviously) fake SEK 20 notes. They were explicitly instructed to make their decisions as if the notes were real, but they were also told that the experiment was hypothetical. At the very end of the experiment, they were given an envelope with the real SEK 20 notes according to the decision made by a randomly paired dictator in one of the previous sessions. The results from the hypothetical dictator game as well as from the follow-up questions are reported in Section 4.

The post-experimental survey in Experiment 3 is, with a few small exceptions, identical to the survey in Experiment 2. The complete instructions and post-experimental survey is reproduced in the Appendix.

\section{Results}

\subsection{Dictator behavior}

Figure 1 and Table 1 below summarize the main results of the (real money) dictator games in all experiments. In Experiment 1, the average donation under high cognitive load $(28 \%$ of the endowment) is smaller than under low load (30\% of the endowment), but the difference is not statistically significant according to either a t-test or a Wilcoxon-Mann-Whitney (WMW) test. The median donation is $20 \%$ under both high and low cognitive load. All subjects in the low cognitive load task remembered the 7-digit sequence correctly, while all but one in the high cognitive load task did. Hence, it may be questioned whether memorizing the 7-digit number indeed induced cognitive load.

In Experiment 2 we similarly find small effects of cognitive load. In this experiment, subjects under high cognitive load are slightly more selfish than those under low cognitive load, but again the differences between treatments are not statistically significant. The results from the choices of the receivers, as well as the timing decision and follow-up questions, are reported in Section 4.3.

In Experiment 3, there are again very small differences between high and low cognitive load across all treatments, neither of which are statistically significant. All subjects remembered the easy sequence (low cognitive load), whereas $42 \%$ and $67 \%$ remembered the difficult sequence (high cognitive load) correctly among dictators and recipients, respectively, thus indicating the intended effect of cognitive load. 


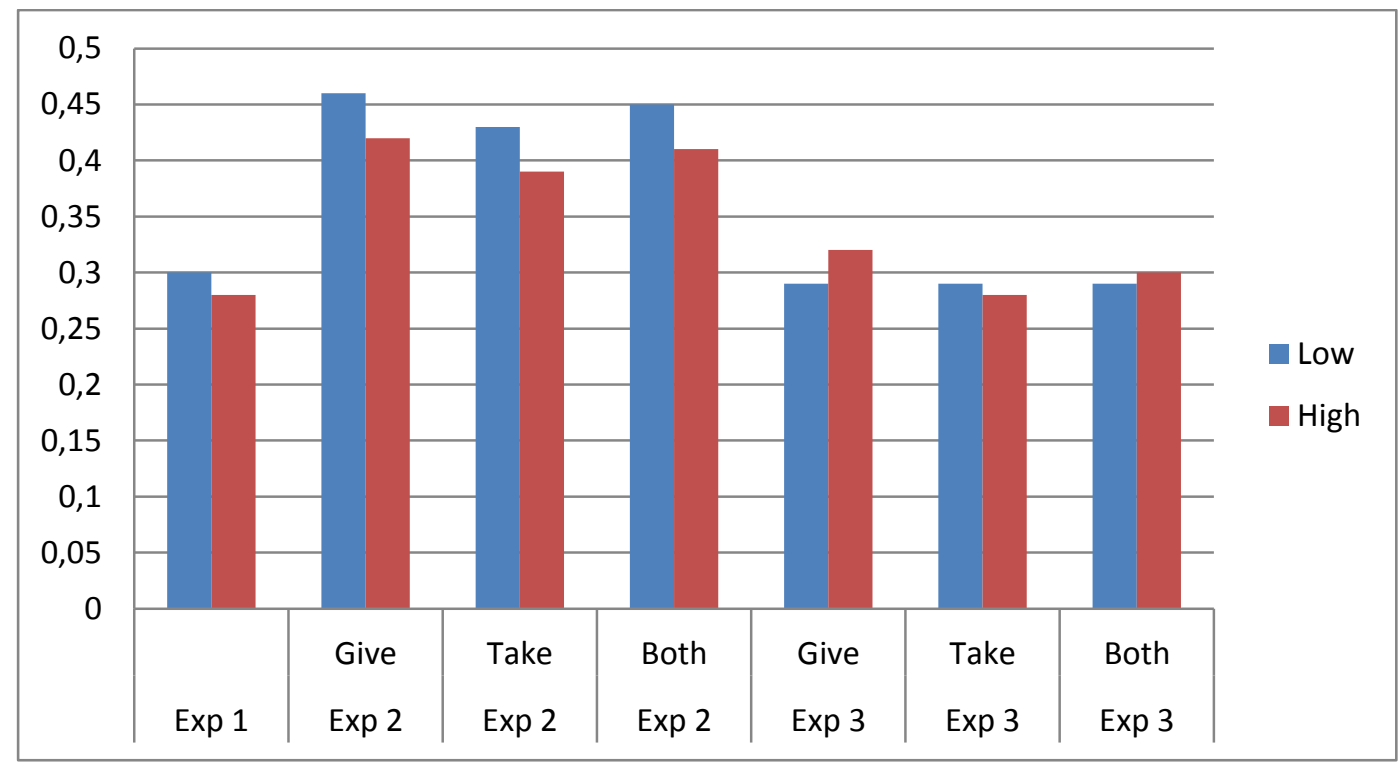

Figure 1. Average dictator allocations in share of endowment, by experiment and treatment.

Table 1. Average share of endowment allocated by the dictators under low and high cognitive load, respectively, for the different experiments.

Average share allocated to receiver Prob. value

(number of subjects)

\begin{tabular}{llll}
\hline Low cognitive & $\begin{array}{l}\text { High } \\
\text { load }\end{array}$ & cognitive t-test & WMW test
\end{tabular}

Experiment 1
$0.30(n=25)$
$0.28(n=32)$
0.761
0.9933

\section{Experiment 2}

$\begin{array}{lllll}\text { Give treatment } & 0.46(n=28) & 0.42(n=33) & 0.2838 & 0.4188 \\ \text { Take Treatment } & 0.43(n=28) & 0.39(n=33) & 0.3734 & 0.3887 \\ \text { Both treatments } & 0.45(n=28) & 0.41(n=33) & 0.1730 & 0.2342\end{array}$

\section{Experiment 3}

$\begin{array}{lllll}\text { Give treatment } & 0.29(\mathrm{n}=20) & 0.32(\mathrm{n}=19) & 0.6744 & 0.8144 \\ \text { Take Treatment } & 0.29(\mathrm{n}=17) & 0.28(\mathrm{n}=18) & 0.9117 & 0.7265 \\ \text { Both treatments } & 0.29(\mathrm{n}=37) & 0.30(\mathrm{n}=37) & 0.8433 & 0.9142\end{array}$

A regression of the pooled results from both Experiment 2 and 3 is given in Table 2. The regression controls for age and gender and also different aggregates from the post experiment Panas- $\mathrm{X}$ emotion questionnaire. We return to the questionnaire below, and focus now only on the first column where 
we only control for age and gender. The results confirm the pattern from Table 1 . Cognitive load has a small negative effect on the relative amount the dictators allocate to others, but the effect is not significant. The only significant effect is a small negative effect of higher recall, but the effect is hard to interpret. Subjects with better recall may have put more emphasis on this task, implying a higher cognitive load, or they may have found the task easy, indicating a low load.

Table 2: Regression on the relative amount dictators gave to recipients.

\begin{tabular}{|c|c|c|c|c|}
\hline & $\begin{array}{l}\text { (1) } \\
\text { Relative } \\
\text { allocation }\end{array}$ & $\begin{array}{l}(2) \\
\text { Relative } \\
\text { allocation }\end{array}$ & $\begin{array}{l}(3) \\
\text { Relative } \\
\text { allocation }\end{array}$ & $\begin{array}{l}(4) \\
\text { Relative } \\
\text { allocation }\end{array}$ \\
\hline Load & $\begin{array}{l}-0.0432 \\
(-0.90)\end{array}$ & $\begin{array}{l}-0.0623 \\
(-1.36)\end{array}$ & $\begin{array}{l}-0.0454 \\
(-0.87)\end{array}$ & $\begin{array}{l}-0.0467 \\
(-1.05)\end{array}$ \\
\hline Recall & $\begin{array}{l}-0.0740 * \\
(-1.93)\end{array}$ & $\begin{array}{l}-0.0951 * * \\
(-2.43)\end{array}$ & $\begin{array}{l}-0.0684 \\
(-1.11)\end{array}$ & $\begin{array}{l}-0.0951^{* *} \\
(-2.38)\end{array}$ \\
\hline Give frame & $\begin{array}{l}0.0108 \\
(0.30)\end{array}$ & $\begin{array}{l}0.00214 \\
(0.06)\end{array}$ & $\begin{array}{l}0.0333 \\
(1.14)\end{array}$ & $\begin{array}{l}0.0143 \\
(0.40)\end{array}$ \\
\hline Load*frame & $\begin{array}{l}0.00884 \\
(0.19)\end{array}$ & $\begin{array}{l}0.0231 \\
(0.50)\end{array}$ & $\begin{array}{l}-0.00734 \\
(-0.19)\end{array}$ & $\begin{array}{l}0.00346 \\
(0.07)\end{array}$ \\
\hline Age & $\begin{array}{l}-0.00199 \\
(-1.00)\end{array}$ & $\begin{array}{l}-0.00261 \\
(-1.26)\end{array}$ & $\begin{array}{l}0.00156 \\
(1.35)\end{array}$ & $\begin{array}{l}-0.00243 \\
(-1.21)\end{array}$ \\
\hline Female & $\begin{array}{l}0.00275 \\
(0.07)\end{array}$ & $\begin{array}{l}0.0138 \\
(0.33)\end{array}$ & $\begin{array}{l}-0.0120 \\
(-0.23)\end{array}$ & $\begin{array}{l}0.0143 \\
(0.35)\end{array}$ \\
\hline Positive emotions & & $\begin{array}{l}0.0335^{*} \\
(1.80)\end{array}$ & & \\
\hline Negative emotions & & $\begin{array}{l}-0.0599 * * \\
(-2.17)\end{array}$ & & \\
\hline Attentiveness & & & $\begin{array}{l}-0.0216 \\
(-0.81)\end{array}$ & $\begin{array}{l}0.00421 \\
(0.23)\end{array}$ \\
\hline Self-assurance & & & $\begin{array}{l}0.0355^{*} \\
(1.97)\end{array}$ & \\
\hline Guilt & & & $\begin{array}{l}-0.0879^{*} \\
(-1.97)\end{array}$ & $\begin{array}{l}-0.0755^{\text {**** }} \\
(-3.40)\end{array}$ \\
\hline Serenity & & & $\begin{array}{l}-0.0429 \\
(-1.33)\end{array}$ & \\
\hline Constant & $\begin{array}{l}0.498 * * * \\
(5.28)\end{array}$ & $\begin{array}{l}0.535 * * * \\
(4.00)\end{array}$ & $\begin{array}{l}0.719 * * * \\
(2.81)\end{array}$ & $\begin{array}{l}0.634 * * * \\
(4.77)\end{array}$ \\
\hline $\mathrm{N}$ & 194 & 191 & 120 & 190 \\
\hline $\mathrm{R} 2$ & 0.0250 & 0.0679 & 0.108 & 0.0837 \\
\hline
\end{tabular}

$t$ statistics in parentheses

$* \mathrm{p}<0.10, * * \mathrm{p}<0.05, * * * \mathrm{p}<0.01$ 

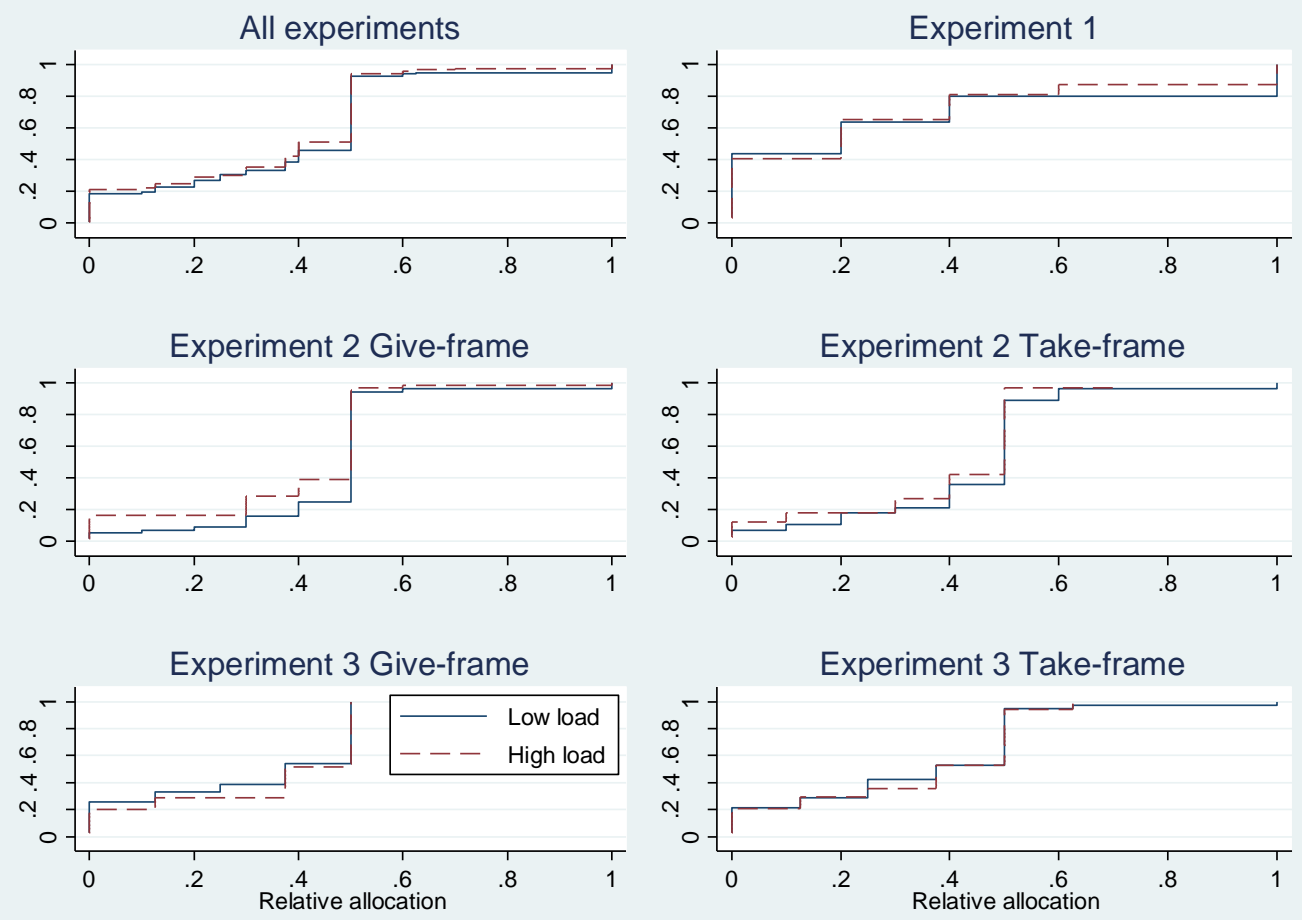

Figure 2: Cumulative distribution of allocations in share of endowment, by experiment and treatment. 
Figure 2 illustrates the cumulative distribution of allocations by experiment and treatment. As can be seen, dictator allocations follow the typical pattern observed in dictator games in the literature, where a large share of the subjects gave either nothing (20\%) or split the endowment equally $(45 \%)$. From a dual process perspective, typical allocation behavior such as sharing equally or taking everything could be seen as heuristic strategies that require no, or very little, conscious effort. On the other hand it is also possible that sharing equally or taking everything is based on deliberation and thus can be affected by cognitive load. To check this, we constructed two dummy variables intended to represent these two typical allocations. The variable equal is one if the person allocated $50 \%$ to the receiver, otherwise zero. Similarly, egoist is equal to one if the dictator allocated zero to the other ${ }^{9}$. The results based on data from Experiments 2 and 3 are provided in Table 3 . There is no significant effect of cognitive load, neither on equal nor on egoist choices. Thus, our results do not support the claim in Rand et al. (2012) that giving is spontaneous and greed is calculated. Female allocate more evenly, and the give frame also induces more equal distributions while older subjects are more egoistic, but these effects are only significant at the $10 \%$ level.

Table 3. Regressions on the dummy variables equal and egoist

\begin{tabular}{lll}
\hline & $(1)$ & $(2)$ \\
& Equal & Egoist \\
\hline Load & 0.0121 & 0.0124 \\
& $(0.13)$ & $(0.19)$ \\
Give frame & $0.132 *$ & -0.0135 \\
& $(1.86)$ & $(-0.24)$ \\
Load*frame & -0.0671 & 0.0390 \\
& $(-0.67)$ & $(0.50)$ \\
Age & -0.00125 & $0.00557 *$ \\
& $(-0.31)$ & $(1.69)$ \\
Female & 0.103 & $-0.0802 *$ \\
& $(1.58)$ & $(-1.67)$ \\
Constant & $0.429 * * *$ & 0.0635 \\
& $(3.28)$ & $(0.64)$ \\
\hline $\mathrm{N}$ & 327 & 327 \\
$\mathrm{R} 2$ & 0.0217 & 0.0300 \\
\hline$t$ statistics in parentheses & \\
$* \mathrm{p}<0.10, * * \mathrm{p}<0.05, * * * \mathrm{p}<0.01$ &
\end{tabular}

\subsection{Stated behavior}

The receivers in Experiments 2 and 3 stated the sum of money that they thought would be morally right to give to their partner. As can be seen in Table 4, again we obtained no significant differences between the high and low cognitive load treatments. The recipients also made similar choices as the dictators, with the only difference that they used hypothetical instead of real money. Again, we obtained no differences between either cognitive load treatments or between the give and take treatments, see Table 4.

\footnotetext{
${ }^{9} 45 \%$ of the subjects gave exactly $50 \%$ of the endowment while $20 \%$ of the subjects gave nothing. We have also tried to define equal as giving between $40 \%$ and $60 \%$ of the endowment and egoist as giving less than $10 \%$. The results are similar.
} 
Table 4: Receivers' stated behavior. Give treatment only.

\begin{tabular}{|l|l|l|l|l|}
\hline & \multicolumn{2}{|l|}{ Share contributed to receiver } & \multicolumn{2}{l|}{ Prob. Value } \\
\hline & Low cognitive load & High cognitive load & t-test & WMW test \\
\hline Stated morally superior value & $0.49(n=28)$ & $0.48(n=33)$ & 0.543 & 0.7639 \\
\hline Experiment 2 & $0.51(n=40)$ & $0.46(n=32)$ & 0.2351 & 0.2493 \\
\hline Experiment 3 & $0.45(n=28)$ & $\underline{0}$ & \\
\hline Hypothetical dictator game & $0.36(n=33)$ & 0.1119 & 0.0841 \\
\hline Experiment 2 & $0.36(n=40)$ & $0.38(n=32)$ & 0.5892 & 0.4021 \\
\hline Experiment 3 & & & \\
\hline
\end{tabular}

However, although not the major task of our paper, it is interesting to note that the hypothetical dictators on average gave substantially more compared to the actual dictators (cf. Table 1 above).

\subsection{Intertemporal preferences}

In Experiment 2, subjects could choose whether their earnings in the experiment should be transferred to their bank account the same day of the experiment or one month later and increased by one-third. Nineteen subjects ( 9 under high cognitive load) chose the immediate transfer, while 103 subjects ( 57 under high cognitive load) chose a delayed transfer. A Chi-square test indicates that there is no statistically significant relationship between cognitive load and intertemporal preferences (chi2 $=0.4105$, prob $=0.522$ ).

\subsection{Follow-up questions and emotions}

In the post experimental survey in Experiments 2 and 3, subjects stated agreement/disagreement on a 7-point scale with the statement "My decision was (guided by) ... thoughts/ feelings/ emotional/ rational / considerate/ impulsive". Regressions of the responses are given in Table 5. There is a clearly significant effect of cognitive load on the responses to this question, with subjects under high load stating that their decisions were less rational and less guided by thoughts and more impulsive and based on feelings. This indicates that the memory task given in Experiment 2 and 3 did in fact induce a high cognitive load. 
Table 5:Regressions on whether choices were...

\begin{tabular}{|c|c|c|c|c|c|c|}
\hline & $\begin{array}{ll}\text { driven } & \text { by } \\
\text { thoughts } & \end{array}$ & $\begin{array}{l}\text { driven by } \\
\text { feelings }\end{array}$ & emotional & rational & $\begin{array}{l}\text { consider } \\
\text { ate }\end{array}$ & impulsive \\
\hline Load & $\begin{array}{l}-0.343^{* *} \\
(-2.09)\end{array}$ & $\begin{array}{l}0.429 * \\
(1.68)\end{array}$ & $\begin{array}{l}-0.175 \\
(-0.70)\end{array}$ & $\begin{array}{l}-0.400^{*} \\
(-1.82)\end{array}$ & $\begin{array}{l}-0.223 \\
(-1.28)\end{array}$ & $\begin{array}{l}0.525 * * \\
(2.15)\end{array}$ \\
\hline Give frame & $\begin{array}{l}-0.0537 \\
(-0.40)\end{array}$ & $\begin{array}{l}0.105 \\
(0.69)\end{array}$ & $\begin{array}{l}0.237 \\
(1.31)\end{array}$ & $\begin{array}{l}-0.0901 \\
(-0.66)\end{array}$ & $\begin{array}{l}-0.220 * \\
(-1.74)\end{array}$ & $\begin{array}{l}0.244 \\
(1.56)\end{array}$ \\
\hline Load*frame & $\begin{array}{l}-0.0215 \\
(-0.12)\end{array}$ & $\begin{array}{l}0.0186 \\
(0.09)\end{array}$ & $\begin{array}{l}-0.139 \\
(-0.58)\end{array}$ & $\begin{array}{l}0.0789 \\
(0.41)\end{array}$ & $\begin{array}{l}0.00165 \\
(0.01)\end{array}$ & $\begin{array}{l}-0.118 \\
(-0.53)\end{array}$ \\
\hline Age & $\begin{array}{l}-0.0142 * \\
(-1.70)\end{array}$ & $\begin{array}{l}-0.00388 \\
(-0.33)\end{array}$ & $\begin{array}{l}-0.00604 \\
(-0.48)\end{array}$ & $\begin{array}{l}-0.0136 \\
(-1.40)\end{array}$ & $\begin{array}{l}-0.00874 \\
(-0.99)\end{array}$ & $\begin{array}{l}-0.00916 \\
(-1.06)\end{array}$ \\
\hline Female & $\begin{array}{l}-0.269 * \\
(-1.97)\end{array}$ & $\begin{array}{l}0.586 * * \\
(2.34)\end{array}$ & $\begin{array}{l}0.133 \\
(0.55)\end{array}$ & $\begin{array}{l}-0.479 * * \\
(-2.47)\end{array}$ & $\begin{array}{l}-0.0473 \\
(-0.30)\end{array}$ & $\begin{array}{l}-0.0643 \\
(-0.27)\end{array}$ \\
\hline Constant & $\begin{array}{l}4.998 * * * \\
(22.84)\end{array}$ & $\begin{array}{l}2.730 * * * \\
(6.68)\end{array}$ & $\begin{array}{l}2.416 * * * \\
(5.40)\end{array}$ & $\begin{array}{l}4.585^{* * *} \\
(14.70)\end{array}$ & $\begin{array}{l}4.546 * * * \\
(17.28)\end{array}$ & $\begin{array}{l}1.976^{* * *} \\
(5.75)\end{array}$ \\
\hline $\mathrm{N}$ & 194 & 194 & 194 & 194 & 194 & 194 \\
\hline $\mathrm{R} 2$ & 0.0814 & 0.0870 & 0.0205 & 0.0772 & 0.0330 & 0.0455 \\
\hline
\end{tabular}

$t$ statistics in parentheses. $* \mathrm{p}<0.10, * * \mathrm{p}<0.05, * * * \mathrm{p}<0.01$

After the experiment, subjects completed a survey on emotions consisting of selected items from Panas-X. Aggregating the responses in different ways yields different emotional measures. We aggregated in two ways: First we used a simple dichotomy of positive versus negative feelings. Second, we categorized the emotions in four different groups, attentiveness, self-assurance, guilt, and serenity. The correlation with generosity can be seen from the results in Table 2, above. Interestingly generosity is positively correlated with positive feelings and negatively correlated with negative feelings, with the latter being more clearly significant. Using the more disaggregated feelings, we find that generosity is clearly negatively correlated with guilt. These results indicate that generosity induces happiness while greed induces guilt. The results are consistent with the finding in Dunn et al. (2009) that spending money on others generates happiness. 
Table 6: Regression on relative amount allocated to receiver

\begin{tabular}{|c|c|}
\hline & $\begin{array}{l}(1) \\
\text { Relative } \\
\text { allocation }\end{array}$ \\
\hline Load & $\begin{array}{l}-0.0518 \\
(-1.17)\end{array}$ \\
\hline Recall & $\begin{array}{l}-0.0913 * * \\
(-2.33)\end{array}$ \\
\hline Give frame & $\begin{array}{l}0.0139 \\
(0.39)\end{array}$ \\
\hline Load*frame & $\begin{array}{l}0.00328 \\
(0.07)\end{array}$ \\
\hline Age & $\begin{array}{l}-0.000958 \\
(-0.45)\end{array}$ \\
\hline Female & $\begin{array}{l}-0.00459 \\
(-0.12)\end{array}$ \\
\hline "Choice driven by thoughts" & $\begin{array}{l}0.0338^{*} \\
(1.66)\end{array}$ \\
\hline "Choice driven by feelings" & $\begin{array}{l}0.0493 \text { *** } \\
(3.21)\end{array}$ \\
\hline "Choice was emotional" & $\begin{array}{l}-0.0129 \\
(-1.04)\end{array}$ \\
\hline "Choice rational" & $\begin{array}{l}0.0218 \\
(1.28)\end{array}$ \\
\hline "Choice is considerate" & $\begin{array}{l}0.0196 \\
(1.06)\end{array}$ \\
\hline "Choice is impulsive" & $\begin{array}{l}0.0115 \\
(0.77)\end{array}$ \\
\hline Constant & $\begin{array}{l}0.0349 \\
(0.24) \\
\end{array}$ \\
\hline $\begin{array}{l}\mathrm{N} \\
\mathrm{R} 2\end{array}$ & $\begin{array}{l}194 \\
0.146\end{array}$ \\
\hline
\end{tabular}

$t$ statistics in parentheses

$* \mathrm{p}<0.10, * * \mathrm{p}<0.05, * * * \mathrm{p}<0.01$

We also looked at how the relative allocation of dictators correlated with their responses to the question on how the decision was made. The results are given in Table 6. We see that there is a clearly significant correlation between generosity and agreeing with the statement that decisions were guided by feelings. Interestingly, high cognitive load also correlates with decisions being guided by feelings. Still, while this would be consistent with the claim that giving is spontaneous, we find no significant effect of cognitive load on generosity, as discussed above. 


\section{Conclusion}

In this paper we present the results of three experimental distribution games under cognitive load. We used memorization tasks to induce cognitive load on our subjects, largely following the design of Shiv and Fedorikin (1999). The results from the three experiments give consistent results. The responses to the post-experimental questionnaires indicate that harder memorization tasks did in fact induce higher cognitive load, as the subjects under high cognitive load stated that their decisions were more impulsive and driven by feelings, and less rational and driven by thoughts. In spite of this, we find no effect of cognitive load on generosity in the distribution games neither in any of the single experiments nor when pooling the data. Self-interest and concern for others seem to be equally close to our heart, and none of them are more prominently in the mind.

The results from our dictator games are otherwise in line with typical results in the literature, e.g. we find the typical two-humped shape of allocations where a majority of subjects in the dictator games either were greedy (allocated nothing of the endowment) or fair (allocated half the endowment). Rand et al argues that "we propose that cooperation is intuitive because cooperative heuristics are developed in daily life where cooperation is typically advantageous." If greed indeed is calculated, and cognitive load reduces the impact on decisions of cognitive processes such as calculations, one would expect a higher frequency of greedy dictator allocations under cognitive load. In our experiments, cognitive load did not effect the existence of greedy or fair allocations. So in contrast to Rand et al (2012), we do not find support for the claim that greed is calculated, nor do we find the opposite.

As discussed above, other authors have found significant effects of cognitive load on pro-social behavior in lab experiments. One possible explanation for the differences in results may be the nature of the decision tasks studied. While others have used prisoners' dilemma and public good game experiments, we have used simple distribution games. Cooperation in prisoners' dilemma and one-shot public good games involves elements of strategic choice, whereas positive allocations are not confounded by strategic elements, hence potentially providing a closer representation of 'pure' generosity.

A second explanation behind the different conclusions concerning whether pro-social behavior is the result of intuitive or calculated processes, may lie in how the choices themselves and the conditions under which they are made are interpreted. Whereas some authors, as us, use cognitive tasks to induce cognitive load, others use the speed at which decisions are made to infer whether the decisions are driven by intuition or deliberation. Indeed Rand et al (2012) based their conclusion on decision time. However, so did also Piovesan and Wengstrøm (2009) who arrived at the opposite conclusion of Rand et al (2012).

Overall, our finding that subjects under high cognitive load were more likely to report that their decisions were based on feelings, together with no effect found on actual generosity of cognitive load, seem to suggest that generosity is not particularly driven by either feelings or cognition. Still, we encourage future research based on different experimental set-ups to shed further light on these issues.

\section{Acknowledgements}

Thanks to Tore Ellingsen and Magnus Johannesson for good discussions on the design, and to Erik Mohlin and Robert Östling for practical help in conducting experiment 1. Financial support from the Swedish Research Council (Dnr 421-2010-1420) is gratefully acknowledged. 


\section{References}

Andreoni, J. (1995). Warm-glow versus cold-prickle: The effects of positive and negative framing on cooperation in experiments. Quarterly Journal of Economics, 110, 1-21.

Bardsley, N. (2008). Dictator game giving: altruism or artefact? Experimental Economics, 11 (2), 122133.

Benjamin, D. J., S. A. Brown and J. M. Shapiro (forthcoming): Who is "Behavioral"? Cognitive Ability and Anomalous Preferences. Journal of the European Economic Association.

Blackman, D. A. (1999). Is knowledge acquisition and transfer achievable? Research Policy, 27, 36-49.

Brandts, J. and C. Schwieren (2007): Frames and Games, Discussion Paper, Instituto de Análisis Econòmico (CSIC), Barcelona, and University of Heidelberg.

Camerer, C., Loewenstein, G., \& Prelec, D. (2005). Neuroeconomics: How neuroscience can inform economics. Journal of Economic Literature, 43(1), 9-64.

Cappelletti, D., W Güth and M. Ploner (2011): Being of two minds: Ultimatum Offers under Cognitive Constraints. Journal of Economic Psychology 32, 940-950.

Cookson R. (2000): Framing Effects in Public Goods Experiments, Experimental Economics 3, 55-79.

Cornelissen, G., S. Dewitte and L. Warlop (2011): Are Social Value Orientations expressed automatically? Decision making in the dictator game. Personality and Social Psychology Bulletin 37, 1080-1090.

Crelley D., S. Lea and P. Fischer (2008): Ego-Depletion and the Tragedy of the Commons: Self Regulation Fatigue in Public Goods Games. Unpublished manuscript.

Crites S. L., L. R. Fabrigar, R. E. Petty (1994): Measuring the affective and cognitive properties of attitudes: Conceptual and methodological issues. Personality and Social Psychology Bulletin, 20, 619-634.

Cubitt, Robin P, Michalis Drouvelis \& Simon Gächter (2011): Framing and free riding: emotional responses and punishment in social dilemma games. Experimental Economics, 14: 254-272.

Cubitt, Robin P, Michalis Drouvelis, Simon Gächter \& Ruslan Kabalin (2011): Moral judgements in social dilemmas: How bad is free riding? Journal of Public Economics, 95 (3-4), 253-264.

Dawkins, R. (1989, first edition 1976): The Selfish Gene. Oxford University Press.

Dawkins, R. (1991, first edition 1986): The Blind Watchmaker. Penguin Books.

deWaal, F. (1996): Good natured, The origin of right and wrong in humans and other animals, Harvard University Press.

deWaal, F. (2006): Primates and Philosophers, How Morality Evolved, Princeton University Press. 
deWaal, F. (2010): The Age of Empathy; Nature's Lesson for a Kinder Society, Crown Publishing Group.

Dunn, Elizabeth W., Lara B. Aknin and Michael I. Norton (2008), Spending Money on Others Promotes Happiness, Science, Vol. 319, no. 5870 pp. 1687-1688.

Eckel, C. C. and P. J. Grossman. (1996), Altruism in Anonymous Dictator Games, Games and Economic Behavior 16, 181-191.

Evans, J St. B. T. Evans (2008): Dual-Processing Accounts of Reasoning, Judgment, and Social Cognition. Annual Review of Psychology, 59, 255-78.

Gevins, A. S., and Cutillo, B. C. (1993). Neuroelectric evidence for distributed processing in human working memory. Electroencephalography and Clinical Neurophysiology, 87, 128-143.

Ghiselin, M. T., 1974. The Economy of Nature and the Evolution of Sex. Berkeley, CA: University of California Press.

Gilbert, D., B. R. Gieslser and K. A. Morris (1995): When Comparisons Matter. Journal of Personality and Psychology, 69 (2), 227-236.

Gilbert, D. and D. Krull (1988): Seeing less and knowing more: The benefits of perceptual ignorance. Journal of Personality and Social Psychology, 54 (2), 193-202.

Greene, J. D, R. B. Sommerville, L. E. Nystrom, J. M. Darley, J. D. Cohen (2001): An fMRI investigation of emotional engagement in moral judgement. Science 293: 2105-8.

Haidt, J. (2001): The Emotional Dog and Its Rational Tail: A Social Intuitionist Approach to Moral Judgement. Psychological Review, 108, 814-834.

Haidt, J. (2012) The Righteous Mind - Why Good People are Divided by Politics and Religion, Allen Lane, London.

Johansson, L. O., Eek, D., Capraali, T., \& Gärling, T. (2010). Managers' Tradeoffs Between Equality and Efficiency: Preferences and Emotional Responses. Journal of Applied Social Psychology, 40, 2, 473-495.

Khaneman D. (2003) A perspective on judgement and choice. American Psychologist, 58, 697-720.

Kohlberg, L. (1969): Stage and sequence: The cognitive developmental approach to socialization. In Goslin (ed.) Cognitive development and epistemology, New York: Academic Press.

Liberman, V., Samuels S. M., Ross, L. (2004): The name of the game: predictive power of reputations vs. situational labels in determining Prisoner's Dilemma game moves. Personality Social Psychology Bulletin. 30, 1175-1185.

Lieberman, M.D., K.N. Ochsner, D.T. Gilbert, D.L. Schacter (2001): Do amnesics exhibit cognitive dissonance reduction? The role of explicit memory and attention in attitude change. Psychological Science, 12 (2), 135-140. 
Loewenstein, G. and T. O'Donoghue (2005): Animal Spirits: Affective and deliberative processes in economic behavior. Working paper Carnegie Mellon University

Moskowitz, G. B., Skurnik, I., \& Galinsky, A. D. (1999). The history of dual-process notions, and the future of preconscious control. In S. Chaiken \& Y. Trope (Eds.), Dual-process theories in social psychology. New York: Guilford Press.

Nonaka, I., \& Takeuchi, H. (1995). The knowledge-creating company. Oxford: Oxford University Press.

Park, Eun-Soo (2000): Warm-Glow versus Cold-Prickle: A Further Experimental Study of Framing Effects on Free-Riding, Journal of Economic Behavior \& Organization 43, 405-21.

Petty, R. E. \& Wegener, D. T. (1999). The elaboration likelihood Model: Current status and controversies. In S. Chaiken \& Y. Trope (Eds.), Dual-process theories in social psychology. New York: Guilford Press.

Pillutla, M., \& Murnighan, K. (1996). Unfairness, anger and spite: Emotional rejections of ultimatum offers. Organizational Behavior and Human Decision Processes. 68, 208-224.

Piovesan, MM and E. Wengstöm (2009): Fast or fair? A study of response times. Economic Letters 105 (2), 193-196.

Preston, S. D., \& de Waal, F.B.M. (2002) Empathy: Its ultimate and proximate bases. Behavioral and Brain Sciences, 25, 1-72.

Rand, David, Joshua D. Green and Martin Nowak (2012): Spontaneuous giving and calculated greed. Nature, Vol 489, pp 427-430.

Roch, S.A., J.A.S. Lane, C.D. Samuelson, S.T. Allison and J.L. Dent (2000): Cognitive Load and the Equity Heuristic: A Two-Stage Model of Resource Overconsumption in Small Groups. Organizational Behavior and Human Decision processes, 83, 185-212.

Ross, Lee and Andrew Ward (1996): Naïve realism in everyday life: implications for social conflict and misunderstanding. In: Reed, Edward S., Elliot Turiel and Terrance Brown (Eds) Values and Knowledge. Lawrence Erlbaum Associates, Mahwah, NJ, pp.103-135.

Schulz, J. F., Fischbacher, U., Thöni, C., \& Utikal, V. (forthcoming). Affect and fairness: Dictator games under cognitive load. Journal of Economic Psychology.

Schwarz, N., \& Clore, G. L. (2003). Mood as information: 20 years later. Psychological Inquiry, 14, 294301.

Shiv, B. and A.Fedorikhin (1999). Heart and Mind in Conflict. The Interplay of Affect and Cognition in Consumer Decision Making. Journal of Consumer Research, 26

Shiv, B. and S. Nowlis (2004): The Effect of Distractions While Tasting a Food Sample: The Interplay of Informational and Affective Components in Subsequent Choice. Journal of Consumer Research, 31 (3), 599-608.

Sonnemans, J., A. Schram and T. Offerman (1998): Public Good Provision and Public Bad Prevention: The Effect of Framing, Journal of Economic Behavior \& Organization 34, 143-61. 
Stanovich, K. E., \& West, R. F. (2000). Individual differences in reasoning: Implications for the rationality debate? Behavioral and Brain Sciences, 23, 645-726.

Swann, W.B., J.G. Hixon, A. Stein-Seroussi, D.T. Gilbert (1990): The fleating gleam of praise: Cognitive processes underlying behavioral reaction to self-relevant feedback. Journal of Personality and Social Psychology, 59 (1), 17-26.

Tinghög, Gustav, David Andersson, Caroline Bonn, Harald Böttinger, Camilla Josephson, Gustav Lundgren, Daniel Västfjell, Michael Kircher and Magnus Johannesson (2013). Intuition and cooperation reconsidered. Nature, Vol 498, 81-82.

Trope, Y. and T. Alfieri (1997): Effortfulness and flexibility of dispositional judgment processes. Journal of Personality and Social Psychology, 73 (4), 662-674.

Tversky, A., \& Kahneman, D. (1974). Judgment under uncertainty: Heuristics and biases. Science, 185, $1124-1131$.

Tversky, A. and D. Kahneman (1981): The Framing of Decisions and the Psychology of Choice, Science 211, 453-58.

van Winden, F. (2007): Affect and fairness in economics, Social Justice Research,

Watson, David and Lee Anna Clark (1994): The PANAS-X: Manual for Positive and Negative Affect Schedule -Expanded Form. Psychology Publications, University of lowa, lowa Research Online: http://ir.uiowa.edu/psychology pubs/11/.

Willinger, M. and A. Ziegelmeyer (1999): Framing and Cooperation in Public Good Games: An Experiment with an Interior Solution, Economics Letters 65, 323-28. 


\section{Appendix: Instructions and questionnaires}

\section{Experiment 1 (Stockholm)}

\section{Instructions}

Welcome to this experiment in Economics. The results from this experiment will be used in a research project. It is therefore important that you follow certain rules. It is important that you do not talk or communicate in any other way with any of the other subjects in the experiment during the experiment. Mobile phones must be turned off. If you have any questions during the experiment, please raise your hand and we will come to you and answer your question.

The purpose of the experiment is to study decision making. The experiment will take place in two different rooms, so during the experiment you will be asked to go to the other room. Before you leave this room you will be asked to memorize a number, which you will report when you come to the second room.

You will be called one at a time to memorize a number before leaving this room. Then you will be sent to the next room to report the memorized number and answer some questions. When you have answered the questions, the experiment is finished.

On your way to the second room, you will pass a screen. Behind the screen you will see different alternatives for compensation for participating in this experiment. There is one slip of paper for each alternative. Take the slip that corresponds to your preferred alternative, and then go to room 2 . Hand in the slip to the assistant in room 2 at the same time as you report the memorized number. In addition to being paid according to the alternative on your slip, you will be paid 50 SEK for showing up. If you report the memorized number correctly, you will receive an additional 50 SEK.

\section{Questionnaire}

During the experiment you made a choice regarding your compensation for participating in the experiment. Describe as completely as possible which thought you had when deciding which alternative you chose.

Indicate the basis of your choice on a 7-point scale by circling one of the numbers.

My thoughts/my feelings

My willpower/my desire

My prudent self/my impulsive self

The rational side of me/the emotional side of me

My head/my heart

In the following, you are to think of the hypothetical situation where you give all the 120 SEK to the Red Cross. Please indicate for each word below how well it describes your emotions related to this hypothetical situation. Please circle the number on the 7-point scale that gives the best description. 1 indicates "No such feeling" while 7 indicates "A strong such feeling".

\section{Irritation \\ Anger \\ Contempt \\ Envy \\ Guilt \\ Jealousy \\ Sadness}




Joy
Pride
Happiness
Shame
Fear
Surprise

In the following, you are to think of the hypothetical situation where you give all the 120 SEK to yourself. Please indicate for each word below how well it describes your emotions related to this hypothetical situation. Please circle the number on the 7-point scale that gives the best description. 1 indicates "No such feeling" while 7 indicates "A strong such feeling".
Irritation
Anger
Contempt
Envy
Guilt
Jealousy
Sadness
Joy
Pride
Happiness
Shame
Fear
Surprise

Now think of the hypothetical situation where you give all the 120 SEK to the Red Cross. For each of the five word pairs, please circle the number that best describes how the words describe your thoughts about the situation.
A useful choice/a useless choice
A rational choice/an irrational choice
An uncertain choice/a safe choice
A disadvantageous choice/an advantageous choice
An inadequate choice/a perfect choice

Now think of the hypothetical situation where you give all the 120 SEK to yourself. For each of the five word pairs, please circle the number that best describes how the words describe your thoughts about the situation.
A useful choice/a useless choice
A rational choice/an irrational choice
An uncertain choice/a safe choice
A disadvantageous choice/an advantageous choice
An inadequate choice/a perfect choice

For each of the four words below, please circle the number that best describes you as a person. Do you describe yourself as:

Thoughtful/impulsive

Patient/impatient

Stingy/generous,

Risk loving/risk averse 
Indicate whether you are female or male.

\section{Experiment 2 (Oslo)}

\section{Instructions for everyone}

Welcome to this experiment in Economics. The results from this experiment will be used in a research project. It is therefore important that you follow certain rules. It is important that you do not talk or communicate in any other way with any of the other subjects in the experiment during the experiment. Mobile phones must be turned off, and only material you have received from us may be kept available during the experiment. This means that all bags, jackets, and pens must be put away during the experiment. If you have any questions during the experiment, please raise your hand and we will come to you and answer your question.

The purpose of the experiment is to study decision making. We want to emphasize that all of the information we will give you is correct, and that it would be impossible to publish results in economic journals if the information we give you were not correct.

The experiment will be conducted in two different rooms. Half of you sitting here now will soon go to a different room and continue the experiment there. The other half will continue in this room.

This experiment consists of 2 parts. In each of the parts you will all be asked to memorize some numbers and letters. The memory task is identical in room 1 and 2 . Later in the experiment, all of you will be asked to report what you have memorized.

All participants in the experiment will receive 50 NOK for showing up. In addition, you will receive 50 NOK for each of the two memory tasks reported correctly. This applies to all of you. In addition to this, you can earn more, but how much more depends on the choices that half of you will make.

Please raise your hand if you have any questions. One of us will come to you and answer them.

\section{Instructions for dictators}

The experiment will consist of two parts. In both parts you will face choices that will decide the payments for both yourself and the subjects in the other room. Only one of these parts of the experiment will be paid out, and which part will be paid out will be decided by a random draw at the end of the experiment. Since you do not know which part of the experiment will be decisive for payments, it is wise to regard both decisions as if they were the only decisions.

\section{Part 1}

Now a combination of numbers and letters will be shown on the whiteboard. You will get 15 seconds to memorize it. You may not write it down in any way. You will receive NOK 50 if you report the correct combination of numbers and letters.

Choice 1: You have been assigned a partner from the other room. Who your partner is has been decided by a random draw. The partner in the other room will not know who you are, and you will not know anything about your partner. In the big envelope there are two smaller envelopes, one marked "To my partner" and the other "To me". In the envelope marked "To me", there are 10 slips of paper each worth NOK 30, thus NOK 300 in total. Your partner will be paid in real money the amount corresponding to the number of slips of paper in the envelope "To my partner", while you will be paid the amount corresponding to the number of slips of paper in the envelope "To me". If 
you want to, you can move a number of slips of paper of your choice to the envelope marked "To my partner".

If this part is chosen to be paid out, your partner at the end of the experiment will receive the envelope marked "To my partner".

\section{Time of payment}

The payment from the experiment will be transferred to your bank account today. You can however choose to delay the transfer to your bank account by one month. In this case, the amount you will receive will be increased by one-third (33.3\%). If you for example earn 150 kroner from the experiment, we will increase the amount to 200 kroner if you choose to delay the transfer by one month. On your desk are some small stickers. Please use these to indicate your choice on the choice sheet, and then put the choice sheet in the large envelope.

\section{Part 2}

Now, once again a combination of numbers and letters will be shown on the whiteboard. You will get 15 seconds to memorize it. You are not allowed to write it down in any way. Also in this part of the experiment you will receive NOK 50 if you report the correct combination of numbers and letters.

Choice 2: You have now been assigned a second partner from the other room. Your partner is decided by a random draw. The partner in the other room will not know who you are, and you will not know anything about your partner. In the large envelope there are two smaller envelopes, one marked "To my partner" and the other "To me". In the envelope marked "To my partner", there are 10 slips of paper each worth NOK 30, thus worth NOK 300 in total. If you want to, you can move a number of slips of paper of your choice to the envelope marked "To me". As in part 1 of the experiment, the contents of the envelopes will decide actual payments.

If this part is chosen to be paid out, your partner will receive the envelope marked "To my partner" at the end of the experiment.

\section{Instructions for receivers}

The experiment consists of two parts.

\section{Part 1}

Now a combination of numbers and letters will be shown on the blackboard. You will get 15 seconds to memorize them. You may not write this down in any way.

In this experiment, you will first answer a question that will not influence your payment from the experiment. Imagine the situation where a person receives 300 kroner that he can share between himself and a partner, and he must choose between the alternatives on the paper on your desk. Imagine that he does not know who his partner is, and that the partner does not know who he is. How much do you think is morally right to give to the other person? On your desk are some stickers. Please indicate with a sticker which alternative corresponds to your answer.

\section{Time of payment}

The payment from the experiment will be transferred to your bank account today. You can however choose to delay the transfer to your bank account by one month. In this case, the amount you will receive will be increased by one-third (33.3\%). If you for example earn 150 kroner from the experiment, we will increase the amount to 200 if you choose to delay the transfer by one month. On 
your desk are some small stickers. Please use these to indicate your choice on the choice sheet, and then put the choice sheet in the large envelope.

\title{
Part 2
}

Now once again a combination of numbers and letters will be shown on the blackboard. You will get 15 seconds to memorize it. You may not write it down in any way. Also in this part of the experiment you will receive NOK 50 if you report the correct combination of numbers and letters.

In this experiment there are two types of subjects. In the other group, each subject received 300 kroner and had the possibility of giving some of it to a random partner in this group. You are the partner of one of the subjects in the other room. There is anonymity in the experiment, so none of the subjects will know who their random partner is. Imagine you faced the same choice, i.e., that you received 300 kroner and you had the possibility of giving some of it to a random partner in the other group. How much would you give to the other subject? Please indicate your choice with a sticker.

\section{Questionnaire}

During the experiment, you faced two decisions regarding payment. When answering this questionnaire, please have the last of these two decisions in mind.

Below are many words and phrases describing different emotions and conditions. Read each of them and indicate with a number in front of each word how you felt. Use the following scale to answer to what degree you felt these emotions when you made the last decision. Please indicate with just one number per word. 1) Very slightly or not at all, 2) A little, 3) Moderately, 4) Quite a bit, 5) Extremely.

\author{
Relaxed \\ Irritable \\ Disgusted with myself \\ Relaxed \\ Alert \\ Upset \\ Active \\ Guilty \\ Nervous \\ Proud \\ Shameful \\ At ease \\ Angry at myself \\ Enthusiastic \\ Blameworthy \\ Determined \\ Confident \\ Dissatisfied with self
}

Indicate below by circling one of the numbers on a 5-point scale how well your decision coincides with the following statements. 1) Does not coincide... 5) Coincides very well

My final decision was driven by my thoughts

My final decision was driven by my feelings

My final decision was considerate

My final decision was impulsive

My final decision was rational

My final decision was emotional 
I was stressed when I made my final decision

I regret my final decision

I am content with my final decision

Age

Gender: Female/Male

(Extra question for dictators): In the experiment, you received NOK 300 that you divided between yourself and a partner. You did not know who the other person was, and the other person did not know who you were. How much do you consider it morally right to give to the other person? Mark the alternative that corresponds to your answer. It would be morally right to give

0 kroner
30 kroner
60 kroner
90 kroner
120 kroner
150 kroner
180 kroner
210 kroner
240 kroner
270 kroner
300 kroner
None of the alternatives are morally more right than the others.

\section{Experiment 3 (Gothenburg)}

\section{Instructions}

Welcome to this experiment at the School of Economics. The results of the experiment will be used a research project. It is therefore important that you follow the instructions given. It is important that you do not talk or communicate in any other way with any of the other subjects in the experiment during the experiment.

Mobile phones must be turned off, and only material you have received from us may be available during the experiment. That means that all bags, jackets, and (especially important) pens must be put away during the experiment!

If you have any questions during the experiment, please raise your hand and we will come to you and answer your question.

All information given during the experiment is correct, and all choices you and others make will be paid out.

All choices you make are completely anonymous. No one will find out which decision you made, not even the experimenters. We will only find out how the group behaved on average.

The experiment consists of two parts. In the first part you will see a combination of letters and numbers for some seconds. You will be asked to memorize the combination. Later on you will be asked what the combination was. If you remember it correctly, you will be rewarded with an extra 50 kroner. 
In the second part of the experiment you will make a decision concerning a sum of money. The instructions concerning this choice are in the envelope on your desk. You may not open it before we tell you to do so.

All participants in the experiment will also get 50 kroner in compensation for showing up for the experiment. This money will be paid out at the end of the experiment.

In total the experiment will last approximately 20 minutes.

Do you have any questions?

Note: Do not turn the page or open the envelope before we tell you to do so!

\section{Part 1}

Soon a combination of letters and numbers, in total 7 characters, will be shown for 15 seconds on the whiteboard.

Your task is to memorize the combination. Later on in the experiment you will be asked what the combination was. If you report the correct combination, you will be rewarded with 50 kroner.

Note that you may not write down the characters in any way (and you are not allowed to have a pen)!

After the combination has been shown for 15 seconds, we will ask you to open the envelope. We will read the instructions out load.

\section{Part 2 Dictators}

You will now make a decision regarding the distribution of a sum of money between yourself and a "partner".

This partner is part of another group of students who will come here later today. You will not know who this person is, and this person will not know who you are. We, the experimenters, will not find out how you, or any other person, have behaved. We will only find out how the group on average behaved.

The students in the other group, including your partner, will receive a task that is equally timeconsuming as the task you will do now. They will also receive 50 kroner for participating and an additional 50 kroner if they remember the correct combination of letters and numbers. However, they will not face a decision regarding distributing real money.

In your envelope there are two smaller envelopes, one marked "To my partner" and the other "To me". In the envelope marked "To me"(/"To my partner"), there are eight 20 kroner bank notes, thus 160 kroner in total.

You can now move money between the two envelopes as you wish. The money in the envelope "To me" is yours to keep and you can take it home after the experiment. The money in the envelope "To my partner" will be paid to your partner later today.

Note once again that all decisions are completely anonymous.

The next two hours after the experiment you are not allowed to open the envelope marked "To me". Please do not discuss the experiment with others participating in the experiment.

Please raise your hand when you are finished. Meanwhile, leave the envelope on your desk. 


\section{Part 2 Receivers}

Now you will make a decision concerning a hypothetical distribution of money between yourself and a hypothetical "partner". The experiment is hypothetical, meaning that no real money will be distributed based on your choice, but we ask you to behave as if the experiment concerned real money.

Imagine that your partner is part of another group of students who will come here later today. You will not know who this person is, and this person will not know who you are. We, the experimenters, will not find out how you, or any other person, behaved. We will only find out how the group on average behaved.

Imagine that the students in the other group, including your partner, will receive a task that is equally time consuming as the task you will do now. They will also receive 50 kroner for participating and an additional 50 kroner if they remember the correct combination of letters and numbers. However, they will not face a decision regarding distributing money.

In your envelope there are two smaller envelopes, one marked "To my partner" and the other "To $\mathrm{me}^{\prime}$. In the envelope marked "To me"(/"To my partner"), there are eight copies of 20 kroner bank notes, thus 160 kroner in total.

You can now move copied money between the two envelopes as you wish. Imagine that the money in the envelope "To me" is yours to keep and you can take it home after the experiment. Imagine further that the money in the envelope "To my partner" will be paid to your partner later today.

Note once again that all decisions are completely anonymous.

Please do not discuss the experiment with others participating in the experiment.

Please raise your hand when you are finished. Meanwhile, leave the envelope on your desk.

\section{Questionnaire}

During the experiment, you faced two decisions regarding payment. When answering this questionnaire, please have the last of these two decisions in mind.

Below is a list of words and phrases describing different emotions and conditions. Read each of them and indicate with a number in front of each word how you felt when you divided money between yourself and the receiver. The different numbers 1-5 mean: 1) Very slightly or not at all, 2) A little, 3) Moderately, 4) Quite a bit, 5) Extremely. Please indicate with only one number from 1 to 5 how you felt when dividing the money. I felt:

Relaxed
Irritable
Disgusted with myself
Relaxed
Alert
Upset
Active
Guilty
Nervous
Proud
Shameful
At ease
Angry at myself




\title{
Enthusiastic \\ Blameworthy \\ Determined \\ Confident \\ Dissatisfied with self
}

Indicate below by circling one of the numbers on a 5-point scale how well your decision coincides with the following statements. 1) Does not coincide... 5) Coincides very well

My final decision was driven by my thoughts

My final decision was driven by my feelings

My final decision was considerate

My final decision was impulsive

My final decision was rational

I experienced strong emotions when I made my choice of distribution

I was stressed when I made my choice of distribution

My choice of distribution was morally right

Age

Gender: Female/Male

What is your main field at the university? Please mark the alternative below that best describes your studies.

\author{
Economics \\ Psychology \\ Political science \\ Natural science \\ Technology \\ Law \\ Medicine \\ Business economics \\ Cultural geography \\ Statistics \\ Humanities \\ Philosophy \\ Sociology \\ Language \\ Not a student \\ Other field:
}

Please put the instructions, the questionnaire and the envelope marked "To my partner" in the large envelope. Keep the envelope marked "To me". We will soon come and pay you for participating.

Thanks for participating in the experiment! 